activity, HAQ-DI, and pain as early as Week 2 (first post-baseline assessment), and improvements in fatigue by M3. Responses were maintained or improved through M3 (monotherapy) or M6 (with background csDMARDs).

References:

[1] Curtis JR et al. Arthritis Care Res (Hoboken) 2015; 67:1345-1353.

Acknowledgements: Previously presented at ACR 2016 and reproduced with permission. This study was sponsored by Pfizer Inc. Editorial support was provided by AG McCluskey of CMC and was funded by Pfizer Inc.

Disclosure of Interest: D. Aletaha Consultant for: AbbVie, BMS, Eli Lilly, Janssen, MSD, Pfizer Inc, Roche, and UCB, Speakers bureau: AbbVie, BMS, Eli Lilly, Janssen, MSD, Pfizer Inc, Roche, and UCB, A. Kivitz Grant/research support from: AbbVie, Amgen, Bristol Myers Squibb, Genentech, Pfizer Inc, Consultant for: AbbVie, Amgen, Bristol Myers Squibb, Genentech, Pfizer Inc, Speakers bureau: AbbVie, Amgen, Bristol Myers Squibb, Genentech, Pfizer Inc, G. Valenzuela Speakers bureau: AbbVie, Janssen, Eli-Lilly, Merck, Novartis and Pfizer Inc, J. Tesser Grant/research support from: Pfizer Inc, Consultant for: Pfizer Inc, Speakers bureau: Pfizer Inc, S. Hays Shareholder of: Pfizer Inc, Employee of: Pfizer Inc, H. Li Shareholder of: Pfizer Inc, Employee of: Pfizer Inc, C. A. Connell Shareholder of: Pfizer Inc, Employee of: Pfizer Inc, E. Bananis Shareholder of: Pfizer Inc, Employee of: Pfizer Inc, A. Soonasra Shareholder of: Pfizer Inc, Employee of: Pfizer Inc, J. S. Smolen Grant/research support from: AbbVie, Janssen, Lilly, MSD, Pfizer Inc, and Roche, Consultant for: AbbVie, Amgen, AstraZeneca, Astro, Celgene, Celtrion, Glaxo, ILTOO, Janssen, Lilly, Medlmmune, MSD, Novartis-Sandoz, Pfizer Inc, Roche, Samsung, Sanofi, and UCB, Speakers bureau: AbbVie, Amgen, AstraZeneca, Astro, Celgene, Celtrion, Glaxo, ILTOO, Janssen, Lilly, Medlmmune, MSD, Novartis-Sandoz, Pfizer Inc, Roche, Samsung, Sanofi, and UCB

DOI: 10.1136/annrheumdis-2017-eular.1556

\section{THU0187 DO WE TODAY ALTERNATIVE THERAPIES RHEUMATOID ARTHRITIS TWO OR MORE DISEASE-MODIFYING DRUGS? THE STORY OF HOW A SIMPLE DRUG PENTOXIFYLLINE MAY ENHANCE THE ACTION OF METHOTREXATE IN RHEUMATOID ARTHRITIS}

\section{D.S. Bublikov, D.A. Anchugina, I.E. Babushkin. Altay State Medical University,}

\section{Barnaul, Russian Federation}

Background: The treatment of patients with RA (rheumatoid arthritis) is a complicated task, because the achievement of remission and low level of activity often requires administration of 2-3 disease-modifying drugs. In such conditions we often face with the rise of treatment costs and with the increase of therapy side effects. That is why relevant is the search of the drugs increasing the effect of the "gold standard" of RA - therapy - methotrexate, and also frequently used sulphasalazine and leflunomid. Treatment of prior to "Treat to target" is difficult enough, forcing researchers around the world to look for the ways to improve the effectiveness of RA treatment.

Objectives: To explore the possibilities of reducing RA activity on the disease activity score DAS28 CRP by adding pentoxifylline to the methotrexate, sulfasalazine and leflunomide treatment.

Methods: This study included women $(n=131)$ with RA longer than 1 year in duration, having a seropositive rheumatoid factor, and DAS28 CRP activity score of 3.2-5.1. Middle aged $-46.44 \pm 3.24$ years old. All patients received a $15.50 \pm 2.50 \mathrm{mg}$ oral dose of methotrexate per week, $2000 \pm 500 \mathrm{mg}$ oral dose of sulfasalazine per day, $20 \pm 5 \mathrm{mg}$ oral dose of leflunomide per day. Patients were divided into two groups - those who only had disease-modifying drugs (DMARDs) $(n=80)$ and those who were treated with an oral dose of methotrexate and 1200 $\mathrm{mg}$ of pentoxifylline per day $(\mathrm{n}=51)$.

Results: The baseline for both groups of RA patients did not differ significantly in terms of the level on the DAS28 CRP $(p=0.812)$. On 14th day of the group who were taking pentoxifylline, the DAS28 CRP disease activity score was significantly lower by $12.5 \%(p<0.001)$. After 28 days, the users had a DAS28 CRP disease activity score index difference. The difference between two groups is statistically significant. In the group that were treated with pentoxifylline in addition to DMARDs $(p=0.001)$ the index was found to be $8.3 \%$ lower. For 28 days, the methotrexate group's disease activity according to the DAS28 CRP activity score significantly decreased by $14.3 \%$ from the baseline $(p<0.001)$. For 28 days, the pentoxifylline + DMARDs group also achieved a statistically significant reduction in the index according to the DAS28 CRP activity score by $20.5 \%(p<0.001)$

The disease activity index for the two groups for 14 and 28 days is shown in the table.

The DAS28 CRP Index in the two groups of RA patients

\begin{tabular}{lccc}
\hline $\begin{array}{l}\text { Groups of patients } \\
\text { Observation time }\end{array}$ & $\begin{array}{c}\text { Group } \\
\text { DMARDs } \\
(\mathrm{n}=80)\end{array}$ & $\begin{array}{c}\text { Group DMARDs }+) \\
\text { Pentoxifylline } \\
(\mathrm{n}=51)\end{array}$ & $\begin{array}{c}\text { Statistical significant } \\
\text { differences between } \\
\text { the two groups }\end{array}$ \\
\hline Baseline & $3.11 \pm 0.05$ & $3.13 \pm 0.05$ & $\mathrm{p}=0.812$ \\
For 14 days & $3.06 \pm 0.05$ & $2.69 \pm 0.06$ & $\mathrm{p}<0.001$ \\
For 28 days & $2.71 \pm 0.04$ & $2.48 \pm 0.06$ & $\mathrm{p}=0.001$ \\
\hline
\end{tabular}

Conclusions: Thus, converting the monotherapy DMARDs to pentoxifylline will significantly reduce the activity of RA, while avoiding many of the adverse effects of the other combination therapies. This data requires further long-term research.
Disclosure of Interest: None declared

DOI: 10.1136/annrheumdis-2017-eular.7019

\section{THU0188 EFFICACY AND SAFETY OF TOFACITINIB IN PATIENTS WITH RHEUMATOID ARTHRITIS WHO DID NOT RESPOND TO SYNTHETIC AND BIOLOGICAL DMARDS IN CLINICAL PRACTICE}

E.L. Luchikhina ${ }^{1}$, D. Karateev ${ }^{2}$, A. Misiyuk ${ }^{1}$, N. Demidova ${ }^{1}$, G. Loukina ${ }^{1}$, D. Abdulganieva $^{3}$, A. Baranov ${ }^{4}$, A. Babaeva $^{5}$, L. Evstigneeva ${ }^{6}$, O. Ivanova ${ }^{7}$, V. Mazurov ${ }^{8}$, O. Semagina ${ }^{9}$, A. Sizikov ${ }^{10}$, V. Sorotskaya ${ }^{11}$, E. Nasonov ${ }^{2} .{ }^{1}$ Early arthritis department; ${ }^{2}$ Nasonova Research Institute of rheumatology, Moscow; ${ }^{3}$ Kazan State Medical University, Kazan; ${ }^{4}$ Yaroslavl State Medical University, Yaroslavl; ${ }^{5}$ Volgograd State Medical University, Volgograd; ${ }^{6}$ Ekaterinburg 1 st Regional Clinic Hospital, Ekaterinburg; ${ }^{7} 4$ Voronezh Regional Clinical Hospital, Voronezh; ${ }^{8}$ North-western State Medical University named after I.I.Mechnikov, Saint-Petersburg; ${ }^{9}$ Samara Regional Clinical Hospital, Samara; ${ }^{10}$ Scientific Research Institute of Clinical immunology, Novosibirsk; ${ }^{11}$ 2nd Sity Hospital, Tula, Russian Federation

Background: Tofacitinib (TOFA) is so far the only representative of a new class of Jak-kinase inhibitors in rheumatology. Despite extensive data on TOFA obtained from 3rd phase studies, for use in clinical practice, the information is limited.

Objectives: To study the efficacy and safety of TOFA in RA in clinical practice. Methods: We represent the combined data from two parallel IV Phase open-label observational clinical trials, modelling clinical practice, conducted by very similar protocols in 11 rheumatology centers in Russia. Inclusion criteria were active RA, methotrexate (MTX) failure, and/or other synthetic or biologic DMARDs failure. In total, 142 pts (26 males, 116 females, age $51,5 \pm 12,2$ years, disease duration $88,6 \pm 78,1$ months, $86,6 \% \mathrm{RF}(+), 76,6 \% \mathrm{ACPA}(+), 81,7 \%$ with erosive disease, DAS28-ESR $5,89 \pm 1,03$, SDAI $35,7 \pm 13,4$, HAQ $1,59 \pm 0,64$ ) were included. 32 $(22,5 \%)$ pts had biologics in history. TOFA used in the dose of $5 \mathrm{mg}$ BID for 6 months, with possibility to increase to $10 \mathrm{mg} \mathrm{BID}$ (carried out in 27 pts after $11,3 \pm 2,7$ weeks). 115 (81\%) pts received TOFA in combination with MTX (18 $\pm 4,5 \mathrm{mg}$ per week), 18 with leflunomide or sulfasalazine, 9 pts used TOFA in monotherapy.

Results: $129(90,8 \%)$ pts successfully completed the six-month period of treatment. TOFA was withdrawn due to lack of response in 6 cases, adverse events (AEs) in 4 (pneumonia, arterial hypertension, skin vasculitis, mouth ulcers), withdrawal of informed consent -2 , protocol violation - 1. At month 3 SDAI score decreased to $14,6 \pm 10,9(\mathrm{p}<0,01), 55(42,6 \%)$ pts achieved SDAI LDA and 22 $(17,1 \%)$ SDAl remission; $\mathrm{HAQ}$ decreased to $0,95 \pm 0,61, \mathrm{HAQ} \leq 0,5$ observed in 36 $(27,9 \%)$ pts. After 6 months, SDAl and HAQ scores decreased to $10,5 \pm 8,6$ and $0,83+0,64$ resp. $(p<0,01) ; 81(62,8 \%)$ pts achieved SDAI LDA and $29(22,5 \%)$ SDAI remission; $\mathrm{HAQ} \leq 0,5$ observed in $48(37,2 \%)$ pts. Results of treatment in patients with and without biological DMARDs in history were similar. Pts who needed dose escalation of TOFA had worse results at month 3 compared to others (SDAI $21 \pm 10,2$ and to $13,2 \pm 10,7$ resp., $p=0,02$ ), but after increase of the dose to $10 \mathrm{mg}$ BID at month 6 they showed a slightly better result (SDAI $9,5 \pm 7,1$ and to $10,7 \pm 8,9$ resp., $p=0,54$ ). Only 2 serious AEs (pneumonia and skin vasculitis) observed. We didn't see any case of Herpes zoster in our group.

Conclusions: TOFA was effective in patients with severe RA who did not respond to both synthetic and biological DMARDs (achievement of SDAI LDA in $42,6 \%$ of pts at month 3 and in $62,8 \%$ at month 6). Dose escalation to $10 \mathrm{mg} \mathrm{BID}$ can be useful in $1 / 4$ of patients who do not respond to standard dose of TOFA. TOFA has shown a good safety profile.

Acknowledgements: This scientific study was supported by grant by Pfizer.

Disclosure of Interest: E. Luchikhina Grant/research support from: Pfizer, Biocad, Speakers bureau: Abbvie, Pfizer, Tirupharm, D. Karateev Grant/research support from: Pfizer, Consultant for: Pfizer, Tirupharm, Biocad, Egis, R-Pharm, Novartis, Speakers bureau: Abbvie, Bristol Myers Squibb, Pfizer, Roche, Tirupharm, Biocad, R-Pharm, Novartis, Egis, MSD, UCB, A. Misiyuk: None declared, N. Demidova: None declared, G. Loukina: None declared, D. Abdulganieva: None declared, A. Baranov: None declared, A. Babaeva: None declared, L. Evstigneeva: None declared, O. Ivanova: None declared, V. Mazurov: None declared, O. Semagina: None declared, A. Sizikov: None declared, V. Sorotskaya: None declared, E. Nasonov: None declared DOI: 10.1136/annrheumdis-2017-eular.5475

\section{THU0189 SAFETY OF FOUR TREATMENT REGIMENS IN EARLY RHEUMATOID ARTHRITIS}

E. Fedorenko ${ }^{1}$, G. Lukina ${ }^{2}$, Y. Sigidin ${ }^{3}$, D. Karateev ${ }^{3} .{ }^{1}$ Moscow Clinical Scientific Center; ${ }^{2}$ Moscow Clinical Scientific Center, V.A.Nasonova Research Institute of Rheumatology; ${ }^{3}$ V.A.Nasonova Research Institute of Rheumatology, Moscow, Russian Federation

Objectives: To compare safety data in patients (pts) with early ( $<2$ years duration) RA who were randomised to receive 4 different regimens of treatment.

Methods: One hundred forty-one pts with RA of less than 2 years duration (122 women, mean age 51 years, mean disease duration 24 weeks, mean DAS 28 5,9; 64\% RF-positive,59\% ACCP-positive) were randomly allocated to receive one of the following treatment regimens: methotrexate (MTX, up to $20 \mathrm{mg} / \mathrm{week}$, 
$35 \mathrm{pts}$ ); MTX plus prednisolone (P) $10 \mathrm{mg}$ daily (MTX-P, $34 \mathrm{pts}$ ); MTX-P plus methylprednisolone (MP) $1000 \mathrm{mg}$ intravenously on the first day of treatment (MTX-P-MP, $35 \mathrm{pts}$ ); leflunomide $20 \mathrm{mg}$ daily (LEF, $37 \mathrm{pts}$ ). Duration of treatment was one year. Control points were 3,6 and 12 months from the initiation of therapy. Safety data was assessed at the main control points.

Results: One hundred twenty-seven pts completed the study. Side effects were registered in the same number of patients in each group ( 9 patients; $24,3 \%>26 \%$ ). Therapy had to be stopped in six patients due to side effects: MTX - 1 (depigmentation of the skin), MTX-P - none, MTX-P-MP - 1 (stomatitis) and LEF - 4 (dermatitis-2; pancytopenia with platelet count $43 \times 10^{9} / \mathrm{L}$, erythrocyte $2,9 \times 10^{12} / \mathrm{L}, \mathrm{WBC} 2 \times 10^{9} / \mathrm{L}-1$; angioedema, periorbital edema and dermatitis with itching-1). Other side effects were mild: MTX - 8 pts (dyspepsia-1, elevation of transaminases-6, hair loss-1), MTX-P - 9 pts (Cushing's syndrome - 1, hair loss - 1 , anemia - 1 , elevation of transaminases - 4 , arterial hypertension - 2), MTX-P-MP 8 pts (hair loss-1, dermatitis-1, elevation of transaminases-5, Cushing's syndrome - 1) and LEF - 5 pts (elevation of transaminases-5). At baseline all groups were comparable in their demographic, clinical and radiographic characteristics.

Conclusions: In most cases side effects were moderate or minimal. The most serious side effects, leading to the discontinuation of the therapy, were registered in LEF group. There was no withdrawal of treatment in MTX-P group. Safety profile was the same in all groups.

Disclosure of Interest: None declared

DOI: 10.1136/annrheumdis-2017-eular.6717

\section{THU0190 DERMATOLOGICAL GUIDELINES FOR MONITORING METHOTREXATE TREATMENT REDUCE DRUG-SURVIVAL COMPARED TO RHEUMATOLOGICAL GUIDELINES}

H. Bernelot Moens ${ }^{1}$, F. Busger op Vollenbroek ${ }^{1}$, R. Janssens ${ }^{2}$, C. Doggen ${ }^{3}$. ${ }^{1}$ Rheumatology \& Clinical Immunology; ${ }^{2}$ Dermatology, Ziekenhuisgroep Twente, Almelo; ${ }^{3}$ Health Technology and Services Research, University of Twente, Enschede, Netherlands

Background: Methotrexate (MTX) is widely used in the treatment of psoriasis and psoriatic arthritis (PsA). To prevent MTX-induced adverse events dermatological MTX guidelines advise a higher number and frequency of blood tests than rheumatological guidelines $(1,2)$. These differences are not based on evidence indicating a higher risk for patients with psoriasis compared to PsA.

Objectives: Compare the effects of MTX monitoring strategies by rheumatologists and dermatologists.

Methods: Patients with psoriasis or PsA in a Dutch teaching hospital. Inclusion criteria: start methotrexate (MTX) between 2006 and 2012 and scheduled follow-up by dermatologist or rheumatologist. Exclusions: incomplete availability of lab data. Start and stop dates and dosing of MTX and folic acid, reasons for withdrawal of MTX, numbers and results of laboratory tests performed for MTX safety, occurrence of any serious adverse event (SAE) were retrieved from electronic records.

Results: PsA patients used higher initial and maximum doses of MTX and folic acid, but psoriasis patients had a higher frequency of abnormal liver function tests, resulting in a striking difference in withdrawal of MTX (Table). In PsA MTX was more often withdrawn for remission, and less frequently for ineffectiveness leading to longer drug survival in the first course of treatment. There were no differences in the occurrence of SAE or death between these groups. Hospital admissions related to infection were recorded in $6(3.1 \%)$ PsA vs $4(2.1 \%)$ psoriasis patients.

Table 1. MTX dose, lab results, and reasons for withdrawal

\begin{tabular}{lcc}
\hline & Psoriasis (N=190) & Psoriatic arthritis (N=196) \\
\hline Men, N (\%) & $86(45.3)$ & $95(48.5)$ \\
Age (y), mean (SD) & $52.3(16.2)$ & $51.8(13.8)$ \\
Prior treatment with MTX & $8(4.2)$ & $39(19.9)^{\star \star}$ \\
MTX starting dose (mg/week) & $12.2(3.7)$ & $15.2(3.0)^{\star \star}$ \\
Folic acid starting dose (mg/week) & $4.9(0.7)$ & $8.4(5.6)^{\star \star}$ \\
Duration of first treatment course (months) & $19.0(19.5)$ & $34.3(30.5)^{\star \star}$ \\
Laboratory visits per treatment month & $0.62(0.81)$ & $0.50(0.34)^{\star}$ \\
Abnormal lab results per treatment month & $0.14(0.26)$ & $0.03(0.07)^{\star \star}$ \\
Abnormal lab results per laboratory visit & $0.26(0.39)$ & $0.06(0.11)^{\star \star}$ \\
Reasons for withdrawal of MTX & & \\
$\quad$ Ineffectiveness & $46(24.1 \%)$ & $31(15.8 \%)^{\star}$ \\
$\quad$ Remission & $14(7.3 \%)$ & $21(10.7 \%)$ \\
$\quad$ Abnormal laboratory result & $29(15.2 \%)$ & $8(4.1 \%)^{\star \star}$ \\
$\quad$ Drug toxicity (mild, including infection) & $47(24.6 \%)$ & $52(26.5 \%)$ \\
Serious Adverse Event & $2(1.0 \%)$ & $2(1.0 \%)$ \\
Death (not related to MTX) & $2(1.0 \%)$ & $4(2.0 \%)$ \\
Other & $22(11.6 \%)$ & $15(7.6 \%)$ \\
\hline Numbers: mean (SD), ${ }^{*} P$ value $\leq 0.05 ;{ }^{\star *} P$-value $<0.001($ Fisher's exact test),
\end{tabular}

Conclusions: Monitoring by dermatologists resulted in more abnormal liver function tests and shorter drug survival of MTX. The monitoring strategy by rheumatologists was not associated with increased SAEs. This supports the safety of current rheumatological guidelines and suggests reconsideration of a higher number of liver function tests in dermatological guidelines.

\section{References:}

[1] Menter A, Korman NJ, Elmets $C$ et al. Guidelines of care for the management of psoriasis and psoriatic arthritis. J Am Acad Dermatol. http://dx.doi.org/ 10.1016/j.jaad.2009.03.027.

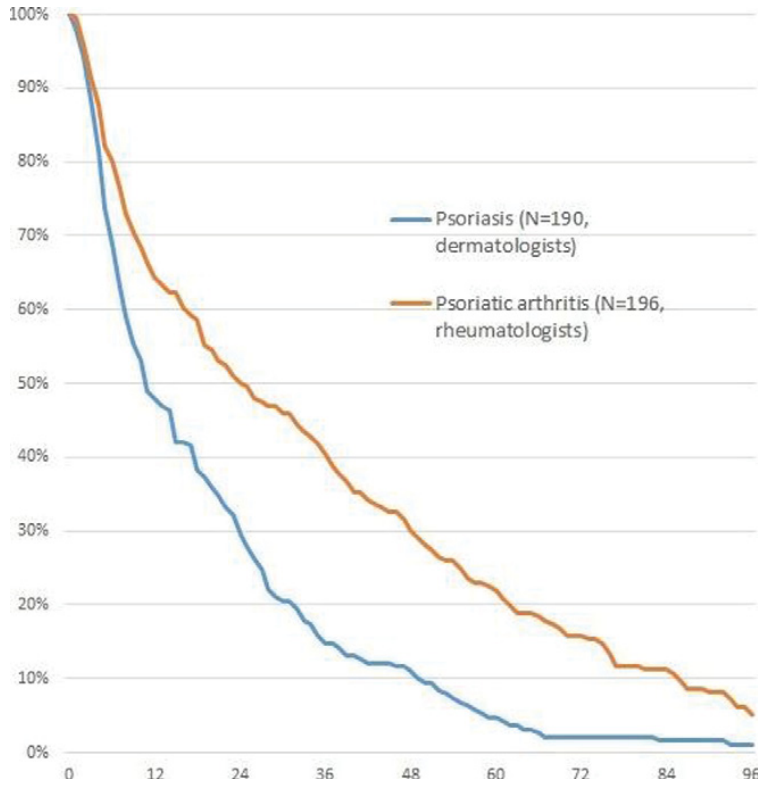

[2] Barker J, Horn EJ, Lebwohl $M$ et al. Assessment and management of methotrexate hepatotoxicity in psoriasis patients: Report from a consensus conference to evaluate current practice and identify key questions toward optimizing methotrexate use in the clinic. J Eur Acad Dermatol Venereol 2011:25:758-64.

Disclosure of Interest: None declared

DOI: 10.1136/annrheumdis-2017-eular.2524

\section{THU0191 EFFECTS OF TOFACITINIB, AN ORAL JANUS KINASE INHIBITOR, ON PATIENT-REPORTED OUTCOMES IN JAPANESE PATIENTS WITH RHEUMATOID ARTHRITIS}

H. Yamanaka ${ }^{1}$, Y. Tanaka ${ }^{2}$, T. Takeuchi ${ }^{3}$, N. Sugiyama ${ }^{4}$, T. Hirose ${ }^{4}$, N. Yoshii ${ }^{4}$, Y. Morishima ${ }^{4}$, S. Toyoizumi ${ }^{4} .{ }^{1}$ Tokyo Women's Medical University, Tokyo; ${ }^{2}$ University of Occupational and Environmental Health, Kitakyushu; ${ }^{3}$ Keio University; ${ }^{4}$ Pfizer Japan Inc, Tokyo, Japan

Background: Tofacitinib is an oral JAK inhibitor for the treatment of rheumatoid arthritis (RA). Improvements in patient-reported outcomes (PROs) have been reported in the global population of the Phase (P)2, P3 and long-term extension (LTE) tofacitinib studies.

Objectives: To explore the effect of tofacitinib on PROs in Japanese patients (pts) with RA.

Methods: In this post hoc analysis, data from Japanese pts with RA were obtained from two 12-week randomised dose-finding $\mathrm{P} 2$ studies in methotrexate (MTX) inadequate responder (IR) and DMARD-IR pts (NCT00603512/A3921039 and NCT00687193/A3921040), one 24-month P3 study in MTX-IR pts (ORAL Scan; NCT00847613/A3921044) and an open-label, LTE study in pts who completed a qualifying P2 or P3 study (NCT00661661/A3921041; completed April 2014). Pts received tofacitinib 5 or $10 \mathrm{mg}$ twice daily (BID) or placebo (PBO) (P2 and ORAL Scan; no PBO in LTE). In ORAL Scan, non-responder PBO pts advanced to tofacitinib at Month 3; all remaining pts were advanced at Month 6 . PROs included: mean change from baseline in Pt's Global Assessment of Arthritis (PtGA; visual analogue scale [VAS]), Physician's Global Assessment of Arthritis (PGA; VAS), Health Assessment Questionnaire-Disability Index (HAQ-DI), Pain (VAS), Functional Assessment of Chronic Illness Therapy - Fatigue (FACIT-F), Medical Outcomes Study (MOS) Sleep Scale and Short-Form Health Survey (SF-36) domain scores. Significance was declared for $p \leq 0.05$ for the P2 and P3 studies reported here.

Results: The analysis included 238 pts from P2 studies, 118 pts from ORAL Scan and 486 pts from the LTE study. Demographics and baseline characteristics were similar between treatment groups for all studies. In P2 studies at Week 12 , tofacitinib 5 and $10 \mathrm{mg}$ BID demonstrated significantly greater improvements from baseline vs PBO in PtGA, PGA, HAQ-DI, Pain, FACIT-F, MOS Sleep Scale and in 4 (Physical Function [PF], Role-Physical [RP], Bodily Pain [BP] and General Health [GH]) of the 8 SF-36 domain scores (Table). Significant improvements in PtGA, PGA, HAQ-DI, Pain and FACIT-F vs PBO were seen as early as Week 2. In ORAL Scan at Month 3, statistically significant improvements from baseline in PtGA, PGA, HAQ-DI and Pain were seen for both tofacitinib 5 and $10 \mathrm{mg}$ BID vs PBO (Table) and these were maintained to Month 24. Significant improvements vs $\mathrm{PBO}$ as early as Month 1 were seen for PGA (tofacitinib $10 \mathrm{mg}$ BID) and Pain (both doses). In the LTE study, mean changes from LTE study baseline in PtGA, PGA, HAQ-DI and Pain were $-32.5,-40.8,-0.5$ and -32.9 , respectively, for all tofacitinib doses at Week 2 , and $-40.7,-50.2,-0.7$ and -42.4 , respectively, at Week 168. Mean changes from baseline in SF-36 domain scores at Week 12 and 